\title{
Exploration \& Analysis of Problems in the Cultivating model of Combination of Work and Study for Higher Vocational Education and Suggestions
}

\author{
You-yun ZHANG ${ }^{1, a}$ and Ping-li MAO ${ }^{2, b}$ \\ ${ }^{1}$ Chongqing Business Vocational College, china \\ ${ }^{2}$ Chongqing Normal University Foreign Trade and Business College, china

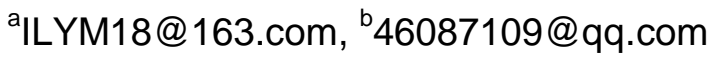

Keywords: Higher vocational education, Combination of work and study, Problems, Suggestions.

\begin{abstract}
The cultivating model - combination of work and study, is an important orientation for the reformation of higher vocational education under the new situation. In recent years, such model has gaind rapid development and initial achievements in higher vocational education. However, there also exist many problems. This article aims at the exploration and analysis of the exsisting problems from both schools and external environment, and put forward the strategical suggestions that schools, enterprises and the government should cooperate with each other with effective measures to optimize the cultivating model of combination of work and study.
\end{abstract}

\section{Introduction}

With the rapid ecomonic development, continual optimization and upgrade of industrial structures of China, more requirements have been put forward for higher vocational education as an approach for the cultivation of talents. For higher vocational education, the combination of work and study is a model that complies with basic rules of vocational education. Based on the requirements of modern economic construction, industrial development and social progress, and for the establishment of mechanism for close cooperation, mutual promotion and benefit between industries (enterprises) and vocational colleges, the model has been regarded as a fundamental objective for the cultivation of talents with high-level qualities and skills. It leads the major innovation and the deep reform of talent-cultivating models of higher vocational education, which is a teaching form of combining students' study with work with features of openess, practical and vocational study. Promoting the new talent-cultivating models that are combining work with study is the responsibility with which society endowed higher vocational colleges, and is also the inevitable choice for the development of higher vocational colleges. 


\section{Connotation and Manifestation of the Training Mode of Combination of Work and Study}

\section{Connotation of Combination of Work and Study Training Mode}

In higher vocational education, students cannot master know-hows in classes but from practices on relevant working posts. Thus, the training mode of work-integrated learning (hereinafter referred to as combination of work and study training mode) was developed. It means to establish an operating mechanism with the industry, enterprises and vocational schools cooperating closely with each other, promoting each other and benefiting each other. It takes adapting to the needs of modern economic construction, industrial development and social progress as the principle, fully observing the basic rules of vocational education and takes cultivating high-quality skilled talents as the fundamental goal. Combination of work and study training mode makes full use of two training environments, school and enterprise, which combination of work and study jointly undertake the task of talent training. As a modern vocational education concept oriented by vocation, it highlights that students should engage in practical work while learning in order to combine school education which mainly gives classroom instructions with off-campus work which mainly provides the opportunity of practices efficiently, help students to gain certain professional practices and work experience, and further enhance their work competitiveness. It's a new-type learning mechanism perfectly combining modern education system and labor system. combination of work and study training mode takes developing students comprehensive quality, professional skills, working capabilities and competitiveness as the core objective. Schools share teacher resources, technologies, equipment and conditions with enterprises, adopt flexible teaching methods and working-integrated teaching mode. In this way, students can spend some time in school to learn basic knowledge and basic skills and some other time to attend practical activities in enterprises organized by the school. Moreover, combination of work and study training mode also observes the principal education concepts, which depends on education content with the orientation of training objective and takes education mode as the concrete realization method.

\section{Manifestation of Combination of Work and Study Training Mode}

In essence, combination of work and study training mode refers to education jointly by schools and enterprises. Students are trained cooperatively. In order to graduate, students need to finish courses in school and practical tasks in enterprises. This mode demonstrates the internal rule and essential requirement of development of vocational education. However, it has diversified manifestations. For example, students can spend some time on basic knowledge, and then go to enterprises to practice under organization of the school; or, they can study and work alternatively. Every week, they can spend some days in school and some days in enterprises, every day, they can learn in school in the morning and practice in enterprises in the afternoon. No matter what way it takes, there's one thing in common. Students need to work while learning. This mode emphasizes "learning while working and working while learning". The specific characteristics are as follows. 1. This mode mainly applies to training of applied and skilled talents; 2. It is a training process with involvement of both schools and enterprises. They should work out and implement the education plan together; 3 . Practical activity is an important part of the education plan and takes a reasonable proportion. It's also an important indicator in performance assessment; 4. Students take 
part in relevant practical activities as the professional workers. In this way, students can both learn relevant theoretical knowledge in school and obtain professional skills in practical bases, and also finish some practical operations in corresponding enterprises.

\section{Problems Existing in the Cultivating Model Combining Work with Study}

\section{Problems from Schools}

Higher vocational colleges are based on the cultivation of technical and practical talents. The cultivating model of combination of work and study is exactly for adjusting to the requirements of society. However, most higher vocational colleges could not fully and scientifically cognize the connotation of "combination of work and study", and deemed that as long as students spend certain time to practice in enterprises, which is already combining work with study. This made school not able to fundamentally change in management mechanisms and teaching systems, therefore, failed to achieve the ultimate objective of combining work with study. Many higher vocational colleges still carried on traditional teaching concepts as before. The major arrangement was disjointed with market requirements, and not closely jointed with requirements of local economic development. Therefore, graduates cultivated by higher vocational colleges did not evidently feature high-level qualities, skills, and application abilities as talents, and were not of market competitiveness. Most of course arrangements still could not adjust to requirements of vocational positions, teaching plans lacked flexibility, and proportions of theoretical courses were still a little high. Both content choices, and methods and measures to implement courses of traditional course models could not adjust to requirements of combining work with study. According to requirements of combining work with study, the logic main line of major courses is practical activities rather than the lecturing of theories, mastered knowledge should be acquired from requirements of actual operational processes of work. If course reform just remains in content integration and form adjustment, and lacks systematical design, it will not be able to support the teaching model combining work with study. Most of teachers teaching in higher vocational colleges immediately directly entered schools and taught after graduating from schools, lacked complete experience in entire work processes and environments of related majors, and lacked deep knowledge and research of practical teaching for related majors. Teachers that were of two types of abilities, truly had rich practical experience, and could guide practice and training for students, were severely lacking. There were fewer teachers could join the development of enterprises' new technology and products. This evidently could not adjust to the objective of higher vocational colleges to cultivate talents with high-level qualities and skills. Levels of teachers' qualities and skills are directly related to quality and levels of vocational education, and are the key to a cultivating model combining work with study. The leaning ability of students of higher vocational education was not strong, the basic operational ability is bad, and the spirit to bear hardship and stand hard work was lacking. Therefore, they exhibited many conditions that could not adjust to teaching combining work with study. When students entered internships of enterprises, they could not understand and accept management models of the enterprises, lacked labor consciousness and concept, and complained about the bitter and laborious. This resulted in the condition that some students were not willing to enter enterprises and study for combining work with study, and this made combining work with study hard to be successfully conducted. 


\section{Problems from External Environment}

The cultivating model combining work with study cannot be carried out by schools as a single aspect. Government's support and enterprises' cooperation are inevitably needed. Moreover, external environments of both these aspects play crucial roles. In recent years, the state has developed a series of policies and measures for energetically developing vocational education. However, local agencies have not adequately responded. They have not developed specific measures to implement in the allowed range of laws, policy systems have not been perfect, implementation mechanisms have not been sound, and they have not been able to substantially guide and promote the cooperation between enterprises and higher vocational colleges. Aspects of teaching-supporting funds, funding investment for construction and others, and regulation mechanisms of the government were also not sound. Firstly, vocational education, as a non-mainline component of the system of education, had a proportion of educational funding that was evidently inadequate. Secondly, same types of schools were repeatedly built without the realization of regional sharing and the usage of equipment and materials was not high; recourse waste emerged to a high extent. Therefore, macro-regulation roles of functional departments of the government still needed further strengthening. Medium for combining work with study is cooperation between schools and enterprises. Without the support and participation of enterprises, the talent-cultivating model combining work with study will lose what it can rely on. Therefore, practical effects resulted from combining work with study depend on the quality of the cooperation between schools and enterprises to a very high extent. Most of enterprises deemed that talent cultivation was responsibility and obligation of vocational colleges, and this resulted in the fact that the combination of schools and enterprises just remained in the pure layer of talent selection. Enterprises did not participate or seldom participate in talent cultivation. Moreover, enterprisers were more willing to share achievements of vocational education rather than take on the responsibility of vocational education. They did not have the positivity to initiatively accept students for practice. Even if some enterprises were willing to cooperate, most of them were also benefit-oriented and just considered students as cheap labor. They were not willing to let practicing students know core technology and secrets of the enterprise. They were afraid that students' nonstandard operation would affect the normal production activities and increase the enterprises' production costs. Moreover, some enterprises' concept was narrow, lacked strategical views for the prospective, and deemed that the investment in vocational education was energy-consuming, could not result in evident benefits. Therefore, their positivity for investing in vocational education was not high. However, conditions and abilities for enterprises to participate in combining work with study also had many shortages. For achieving substantial effects for combining work with study, the cooperated enterprises need to have certain sizes, advanced production equipment, and excellent technological elites, and can select technical staff that match students' majors and have both educational and training experiences for guiding. Many of small \& medium enterprises lack funding and technology, and do not have ability to and are not willing to cooperate with higher vocational colleges. 


\section{Suggestions}

The cultivating model of the combination of study and work is a new learning system that organically combines modern educational systems with labor systems. It combines students' learning in classes with actual work to cultivate their comprehensive abilities, therefore enhances the core competitiveness for employment and better forms talent-cultivation mechanisms to promote students' progress. After analyzing and considering existing problems, for the further development of cultivating model combining work with study in higher vocational education, the following several suggestions were given: (1) Break traditional cultivating models that center on teachers using classes as the pivot and theoretical teaching as the core; reform major arrangements, course objectives, teaching plans and content, teaching methods and measures, and so on; and ensure the deep combination of industries and schools; (2) engage and employ technical elites and skilled craftsmen that have strong professional abilities, practical abilities and rich practical experiences from enterprises and industries to fill the team of teachers; (3) let teachers regularly do to enterprises and take on roles for exercising, make teachers understand enterprises' new technology, crafts and their application in time, and be somewhat familiar with operational management, labor organization, and technology and crafts in the front line of production; (4) establish stable bases for practical training and practice and ensure the needs for practical teaching; (5) the government needs to speed up the development of operational policies and regulations for guiding and supervising, and guarantee the spread of the talent-cultivating model combining work with study; (6) the government need to fully bring the leading role and macro-regulation role into play, mobilize industries' and enterprises' positivity to support higher vocational education, innovate new long-term effective mechanisms for the cooperation between schools and enterprises; (7) set up special institutions to strengthen the communication between government, industries, enterprises and schools, coordinate and resolve issues faced during the cooperation between schools and enterprises; (8) enterprises should change their concept, consider combining work with study as the way to cultivate, select and reserve technical talents for the sustainable development of the enterprises; (9) in the cooperation between schools and enterprises for teaching, enterprises should be transformed from supporting roles into the protagonists, go to the front from behind the scenes, be transformed from passive partners into major investors, and truly become bases for practical training of higher vocational education outside schools.

\section{References}

[1] DING Jinchang \& TONG Weijun. Further Cognition of the Promotion for the "The Cooperation between Schools and Enterprises for Combining Work with Study" of Higher Vocational Education [J]. Journal of Higher Education, 2008, (6):49-55. In Chinese

[2] XIE Chunshan \& BAO Lili. Analyses of Factors Affecting the Cultivating model "Combining Work with Study" [J]. Journal of Liaoning Educational Administration Institute, 2009, (11):45-48. In Chinese

[3] CHEN Songzhou. Problems in and Strategies for the Promotion of the Talent-cultivating model Combining Work with Study for Higher Vocational Colleges [J] . Journal of Southern Vocational Education, 2011,(1);29-34. In Chinese 
[4] Huang Bin. Discussion on Some Issues concerning the Training Mode of Work-Integrated Learning [J]. Education Exploration, 2008 (3):79-80. In Chinese

[5] Guo Zhanmiao. Problems faced by Vocational Schools when Implementing the Training Mode of Work-Integrated Learning and the Countermeasures[J].Journal of Changsha Aeronautical Vocational and Technical College,2010,(10):1-4. In Chinese

[6] Cheng Jun. Value Judgment, Difficulties and Countermeasures of the Training Mode of Work-Integrated Learning in Vocational Education [J]. China Higher Education Research, 2012, (2);89-92. In Chinese 